\title{
Power Imbalances in Mediation
}

\author{
Ali Khaled Qtaishat ${ }^{1}$ \\ ${ }^{1}$ Department of Comparative Law, Faculty of Sheikh Noah El-Qudha for Sharia and Law, World Islamic Science \\ \& Education University, Amman, Jordan \\ Correspondence: Ali Khaled Qtaishat. E-mail: draliq130@gmail.com
}

Received: November 27, 2017 Accepted: December 4, $2017 \quad$ Online Published: January 29, 2018

doi:10.5539/ass.v14n2p75

URL: https://doi.org/10.5539/ass.v14n2p75

\begin{abstract}
The power imbalance in mediation can use of tactics and strategies employed by an intelligent mediator may well balance the power dynamics in a mediation process. Thus the role of mediator becomes very significant vis-à-vis power imbalance. The present paper will first try to highlight the issue of power imbalance and its implications, and then analytically explore the ways and means of eliminating or minimizing or controlling any power imbalance in mediation process
\end{abstract}

\section{Introduction}

Mediation of late has emerged as an effective ADR mechanism. Globally it is experiencing a boom especially in US, Canada, Europe, Australia etc. ${ }^{1}$ In India too, the practice of mediation has fast picked up with setting up of good number of Mediation Centres across the country. Mediation process is considered cheap, flexible and efficient with features like party autonomy, neutrality of mediator, confidentiality, etc. However, about mediation, it is said that it provides "private justice behind closed doors". What goes inside such closed doors is business of nobody except the disputants and mediator. In such a scenario there is a fair amount of likelihood of one party dominating the other during the mediation. This might lead to skewed settlement agreement or an agreement which is an outcome of power imbalance of the parties. Whether such agreement seems just and equitable? Or more precisely, whether mediation offers participants the same "procedural fairness" as the courts do? The answer is probably "NO" if mediation suffers from manifest power imbalance. Some of the instances could be mediation involving a woman and her husband over a matrimonial dispute; or an employment dispute between a small level employee and the corporation itself; or a business dispute between large and small trading companies etc. Power imbalance can also occur where one of the parties is state government or its powerful formal machinery. Thus the question of power imbalance in mediation has posed a serious challenge to the overall effectiveness of this ADR process. Critics point out that this negative feature of mediation makes it a tool in the hands of a powerful party to achieve its skewed purpose, which it may not get through court process. Having said this, it does not mean that power imbalance in mediation cannot be addressed properly. A range of tactics and strategies employed by an intelligent mediator may well balance the power dynamics in a mediation process. Thus the role of mediator becomes very significant vis-à-vis power imbalance. The present paper will first try to highlight the issue of power imbalance and its implications, and then analytically explore the ways and means of eliminating or minimizing or controlling any power imbalance in mediation process.

\section{Mediation: What Does It Offer?}

Mediation, as it widely understood and practiced, is an alternative and amicable mechanism to settling the disputes. In it the third party who is a neutral (mediator) is approached by the disputants and he attempts to bring the disputants to come to a negotiated settlement. The mediator does not impose any decision, but he basically persuades and facilitates the disputants to reach to an amicable understanding, thereby diffusing the crisis and leading to facilitated settlement. In the words of Prof. Laurence Boulle:

"Mediation is a process in which the parties to a dispute, with the assistance of a dispute resolution

\footnotetext{
${ }^{1}$ Mediation graph is rising in prominent jurisdictions of the world. In contemporary times, it has been in use in the dispute resolution arena for the last 20 years. The potential advantages of mediation, in contrast to litigation and to an extent to arbitration, are understood by this fact that a well-timed mediation can result in significant savings of time and cost, enabling the parties to focus on their core activities as opposed to conflicts, and give them the control over the outcomes of their conflicts that they would not otherwise have had. For the latest trend see, Clifford Chance, International Mediation: Global Trend, (March, 2013), available at http://www.cliffordchance.com/publicationviews/ publications/2013/03/international_mediationglobaltrends.html (Last accessed Sep.15, 2017)
} 
practitioner (the mediator), identify the disputed issues, develop options, consider alternatives and endeavour to reach an agreement. The mediator has no advisory or determinative role in regard to the content of the dispute or the outcome of its resolution, but may advise on or determine the process of mediation whereby resolution is attempted." 2

Mediation maybe resorted to on voluntary basis or under a court order, or subject to an existing contractual agreement. Further the use of the term 'alternative' in the context of mediation process essentially means that it is for the parties, if they have mutually agreed to, to choose such a process as an alternative to the court battle.

In addition, mediation comprises a variegated yet structured process guided by five distinct elements, namely, confidentiality, voluntariness, empowerment, neutrality and unique or creative solution. ${ }^{3}$ Each one of them is highly indispensable for an impartial mediated solution. These elements or principles of mediation offer parties or potential disputants a sense of security in the entire mediation proceeding. If anyone of them is compromised or absent, then the resulting outcome cannot be described as based on fair or impartial process. In short we may sum up the significance of these essential features as follows:

"Parties go for mediation 'voluntarily' only when they sense it well that entire mediation process will be 'confidential' and whatever happening during mediation will not be used in any other proceeding including legal one; that they sense it well that the mediator they have chosen will remain 'neutral' and 'impartial' in all circumstances; that the parties will feel 'empowered' in terms of process control ${ }^{4}$, while they proceed with the mediation; and that they will themselves, while being ably facilitated by the mediator, will carve out a 'creative' or 'unique' solution." 5

\section{Is Mediation Systematically Disadvantageous?}

There is no denying the fact that traditional dispute resolution mechanism i.e., litigation or adjudication or court system has performed miserably in rendering justice to the people in timely and efficient manner. Courts are jam-packed with unending number of litigations. There is a kind of 'docket explosion' with the fear of judicial system collapsing. ${ }^{6}$ Disenchantment and frustration against the prevailing justice delivery is visible in all the legal systems across the world. ${ }^{7}$ Such a grim scenario does build up a strong case for mediation and other consensual forms of dispute resolution in a given legal system. In this regard, mediation in particular is vigorously pushed for in several jurisdictions ${ }^{8}$ calling for a shift in judicial and legislative policy. ${ }^{9}$

However, critics argue that mediation suffers from several limitations and shortcomings. As for example, it does not have the formal process; there is no certainty of result; confidentiality cannot always be guaranteed; mediator's impartiality cannot always be maintained; further the process is seen as a weakness on the part of a particular party who shows first interest in mediation; moreover, court mandated mediation amounts to undermining of party's voluntariness, and so on and so forth. In the face of such criticisms, the big question which naturally hits our mind is whether mediation systematically disadvantageous? To answer this question, advocates of mediation will argue that, shortcomings as mentioned above, are true of any dispute resolution

\footnotetext{
${ }^{2}$ L. Boulle \& Alan J. Rycroft, Mediation: Principles, Process, Practice, Butterworths (1997) p. 25

${ }^{3}$ Many commentators adhere to these five basic elements, and according to them, without the presence of such elements, the process cannot be described as a standard mediation. See generally, Lon L. Fuller, The Forms and Limits of Adjudication, Harvard Law Review, Vol. 92, No. 2 (Dec.,1978), pp. 353-409

${ }^{4}$ Parties in mediation have control over the process. This thus gives them a sense of being empowered by such a process, unlike in adversarial court system. See generally, Jacqueline M. Nolan-Haley, The Merger of Law and Mediation: Lessons from Equity Jurisprudence and Roscoe Pound, Cardozo Journal of Conflict Resolution (2004) pp 125-141

5 (Adapted from) Robert A. Baruch Bush, Joseph P. Folger, The Promise of Mediation, Jossey Bass (2005) p 32

${ }^{6}$ See, P.C. Jain, Crisis in Management of Justice - Conciliation Courts, AIR (2004) Joumal Sec., para 6, p 9

${ }^{7}$ It is to be said that none of the legal systems in our world has successfully tackled the problems of delays in their respective courts. However, the problem is more acute in developing and poor countries where delays have become rule. As for example, the number of pending cases in the Indian courts has now crossed 30 million or 3 crore. As of 16-09-2012, there are 31369568 cases pending in the various courts of India. See Policy and Action Plan, National Court Management System, Supreme Court of India, p. 15 (2012). Available at http://supremecourtofindia.nic.in/ncms27092012.pdf (Last accessed Dec. 19, 2013)

${ }^{8}$ As for example, in USA, mediation has become a very prominent feature of its legal system with mediation in recent times happening at a very large scale covering a varieties of disputes. Further, a large number of states in US have enacted laws on mediation. For latest trend of mediation in US and other prominent jurisdictions around the world, see generally, Nadja Marie Alexander, Global Trends in Mediation, Kluwer Law International (2006)

9 There is a great deal of legislative push for mediation in prominent countries around the world. In Europe, the European Union passed an EU Directive on Mediation in 2008, accordingly members of EU have to enact legislation on mediation in order to implement the basic principles of the said Directive.
} 
mechanism including the adjudicatory methods, but mediation's advantages far outweigh its disadvantages. They argue that vested interests do not want to see mediation happening as that would undermine the prestige, power, earning which are generally associated with adjudication in courts. Lawyers in particular see mediation as a great threat in their earning capacity. Moreover, judges see it as something which might corrode their judicial authority. And so the argument and debate continues.

The present paper will not deliver its own value-judgement over the arguments for and against mediation as pointed out above, and especially in the context of the larger question- whether mediation is systematically advantageous or disadvantageous, because doing that will simply put the paper beyond its scope. It is, however, try to discuss and analyse a very critical issue that is of power imbalance in mediation, which is the central question of the present paper as outlined in the beginning.

\section{What Is Power Imbalance in Mediation?}

The term 'power' is defined as 'the ability to influence in a particular desired way', or 'the ability to produce the desired result' or 'the ability to effect a change in the desired way in the relationship' etc. ${ }^{10}$ On the basis of this definition we may describe 'power imbalance' as a skewed or unequal distribution of such abilities in persons. Power imbalance in the human society is a naked harsh reality which each one of us experience in our daily lives on a routine basis.

In the realm of mediation, power imbalance cannot be ruled out rather it is bound to happen given the informal setting of mediation process. Such power imbalance in mediation can manifest in a variety of subtle ways. To illustrate a few, this can happen where one party is better equipped with negotiation skills, knowledge, information; where one has better bargaining power over the other; where one is a big company and the other is a small enterprise or merely an employee of that big company; where one party has greater number of people to his side; where one party has higher status in the society; where one party is illiterate or uneducated about the technical issues discussed in the mediation; where a party is a women coming from a conservative society; where a party is age-wise very senior, etc. The list depicting situations of power imbalances in mediation is not exhaustive and can cover a variety of domestic, formal, informal, social, economic, political, legal relationships between persons.

The votaries of mediation argue that power imbalance is equally true of adjudicatory system wherein a party is invariably pitted against the vast and coercive power of state and/or its machineries. ${ }^{11}$ But they miss the point that in formal, legally well-structured mechanism, there is also a formal means of minimizing the risk of power imbalance in court adjudication. ${ }^{12}$ Further, the court's inherent power can always be invoked where there is likelihood of or actual miscarriage of justice. Further, there are other legal proceedings like appeal, review, revision etc which too are invariably resorted to for addressing the serious questions involving impartial justice if the same has come to happen due to power imbalance.

Hence, it will be a sweeping statement to say that there are power imbalances elsewhere and not only in mediation. The problem gets acute when the votaries of mediation simply refuse to give due recognition to this factor. In the words of Prof. Boulle,

"Giving adequate attention to this inherent problem of mediation that it is most often likely to suffer from power imbalance in actual situation will ultimately lead the theorists to think about how to eliminate or at least minimize this vice, so as to make mediation more effective and acceptable. "13

Further, while comparing with possible power imbalance in adjudication, the one which is likely to happen in mediation can be very subtle and not noticeable easily. ${ }^{14}$ This is reflected in the case where a party is substantially equipped with negotiation powers influencing the mediation process and its outcome through his better placed position as a skilled negotiator. The party who agreed for mediation knowing little about the substantial better negotiating power of the other party, can do little if the resulting award does not reflect what he originally, 'minimally' wanted out of the said process. For such a scenario, the party at disadvantage might remain wholly dissatisfied with the mediation process and will think twice over going for mediation again. Such

\footnotetext{
${ }^{10}$ See, Collins Cobuild Advanced Dictionary (2010)

${ }^{11}$ See generally, Lon L. Fuller, supra n. 3

${ }_{12}$ See generally, Jonathan Crowe, The Problem of Legitimacy in Mediation, The University of Queensland, TC Beirne School of Law Legal Studies Research Paper Series, Research Paper No. 09-10 (2009), available at http://papers.ssrn.com/sol3/papers.cfm?abstract_id=1336370

${ }^{13}$ Supra $\mathrm{n} .2$ at $\mathrm{p} 111$

${ }^{14}$ See generally, Amy J. Cohen, Revisiting Against Settlement: Some Reflections on Dispute Resolution and Public Values, Fordham Law Review, Vol. 78 (2009) pp 1143-1170
} 
a scenario also speaks poorly on mediation process. The same is considered a neutral process where the disputants are more likely to come out 'satisfied' with the mediated settlement. Further, the critical question remains, even where power imbalance has directly or indirectly impacted the mediation process, there is no further remedial action available against such situation ${ }^{15}$ as in the case of adjudicatory process as outlined before Therefore, the need is to strengthen the mediation system from within, so as to address its inherent weaknesses including 'power imbalance' systematically.

\section{Simulated Scenarios}

In several types of mediation like the one which is undertaken for negotiating commercial or business disputes often may entail perceived sense of lack of equilibrium in the status of disputants. In order to understand the same, we may take for instance the following simulated scenarios ${ }^{16}$ :

\section{(A) Case of a Large Energy Company (X) and a Small Local Enterprise (Y):}

In this case a large multinational energy company $(\mathrm{X})$ was facing an on-going contractual dispute related to efficient distribution of electricity in the local areas by a small local enterprise (Y). X was insisting on a pre-negotiated price structure which was later on denied by $\mathrm{Y}$ as highly distorted. Representatives of both $\mathrm{X}$ and Y agreed for the mediation. During the mediation, X's representatives literally outnumbered those of Y. X had high influence in the areas being a multinational giant and $\mathrm{Y}$ being a small local enterprise. The ensuing mediation did result into an agreed solution to the dispute and $Y$ finally agreed to the price structure of energy distribution asE insisted by $\mathrm{X}$ 's representatives, but later on $\mathrm{Y}$ 's representatives complained that mediation process was vitiated due to the fact that during mediation, X's representatives had outnumbered those of Y. That there was considerable amount of coercion and pressure tactics which resulted into skewed outcome so far as $\mathrm{Y}$ was concerned. In other words there was no balance of power in the whole of the mediation process undertaken to settle the dispute between $\mathrm{X}$ and $\mathrm{Y}$.

(B) Case of a Large company (L) and its Shareholders (S):

In this case, L's directors were accused of breaching shareholders' agreement and thus prejudicing them, with the directors of the company selling the shares at a calculated higher price- the value of which was bound to fall in immediate future- which fact was known to company's directors but was kept deliberately secret from shareholders for ulterior purpose. Mediation was offered which both parties agreed to. In the mediation, bullying tactics were openly displayed by company's representatives and they warned that shareholders would lose several benefits if they didn't agree for the policy change of the company. Shareholders' representatives remained divided among themselves over the so-called solution suggested by the company. Further, one group of shareholders' representatives actively supported the company's policy change. After the mediation, another group of shareholders' representatives accused the company of playing foul and using pressure tactics to divide the shareholders. Company denied such allegation but the big question remained whether or not mediation process was vitiated by power imbalance?

(C) Case of Company and its Employees:

Similar simulation may be done with respect to the company and its employees over the wage related dispute or service matters. An employee is but a very small person who may remain threatened by the prospect of job loss or other severe disadvantages in case he or she does not back out from their stated positions against the company's decision. Such a scenario also depicts the presence of power imbalance in the mediation process raising some serious questions on the process as a whole.

\section{Addressing the Issue of Power Imbalance in Mediation}

At the outset it must be conceded that 100 per cent elimination of power imbalance in mediation or for that

\footnotetext{
${ }^{15}$ Because settlement agreement signed by the parties become binding on the parties. And if the party at loss notices power imbalance influencing the process after the signing of the settlement agreement, he or she can do little to offset the award. Legally speaking, knocking the court's door in such situation will be of no avail to the party at loss. Moreover, power imbalance in itself is not a recognized ground to challenge the award rendered in ADR forums. The court might put this valid poser that 'parties must have and should have made an informed decision while going for mediation and signing the settlement agreement, and if either of them had issues over power imbalance, then he or she should have backed out then and there from the process or at least, asked for the redressal within that process itself? See Section 73 of Arbitration and Conciliation Act, 1996, which runs inter alia: When the parties sign the settlement agreement, it shall be final and binding on the parties and persons claiming under them respectively.

${ }^{16}$ Since mediation is a highly private and confidential proceeding, so what went inside is not reported in the public domain unless there has been a post-mediation litigation. Thus in order to understand the cases of mediation, we may simulate the scenarios from the current practices of mediation.
} 
matter in any other forms of dispute resolution is a sheer impossibility. However, as noted above, the threat and risk of power imbalance is a daunting challenge for mediation process. What is needed is to contain and minimize such risk. Herein, thus the question of 'how' assumes significance. This is analysed below:

\section{Recognizing the Power Imbalance Scenario in Mediation:}

This is a very crucial step in minimizing the risk of power imbalance in mediation. Proponents of mediation must agree on this point that mediation potentially suffer from this problem. Mediator in this connection has an astute role to play in bringing it to the knowledge of parties regarding the possibility of power imbalance after considering the overall situation or specific stages of the mediation process. Thereafter, mediator should allow parties to make fully informed decision regarding going with the mediation process. Most importantly, he should privately talk with parties on the issue of power imbalance, if at all it is likely to be an issue or factor in the mediation process. Further, parties own situational analysis ${ }^{17}$ involving possible power imbalance will go a long way in containing the risks associated with it. In any case, what is vitally important is to give due recognition to the factor of power imbalance in mediation, which is a crucial first step in containing its risks.

\section{Mediator's Balancing Role:}

An astute mediator can have a range of mediating tactics which he may employ to balance the power between the parties. Some of such strategies which could be employed by the mediator are as follows:

i. Chalking out the ground rules of dialogue

ii. Picking the topic.

iii. Deciding who may speak.

iv. Controlling the duration of time each person may speak.

v. Allowing and timing a person's response.

vi. Deciding which party may present a proposal to the other.

vii. Presenting an interpretation of what the party said.

viii. Ending the discussion.

ix. Writing down the agreement.

In the above, it is clear that mediator has a lot of power to neutralize the power dynamics of the parties. However, it all depends on the acquired skills and experiences of the mediator to diagnose the power imbalance in mediation at the earliest opportunity, so that he can prepare his tool kit of proper responses.

\section{Other Means of Containing Power Imbalance:}

i. $\quad$ Neutral or safe venue for mediation

ii. Encouraging use of an attorney if power imbalance is unmanageable by the mediator

iii. Assisting each party to obtain all the information needed

iv. Separate sessions

v. Use of caucus

vi. Closely enforcing ground rules

vii. Use of co-mediator

The above mentioned ways and means could also be strategically employed by the mediator depending upon the nature of power imbalance. Hence a lot depends on the astuteness of an experienced mediator.

\section{Concluding Remarks}

Mediation as a form of dispute resolution has nowadays evolved itself into a potent alternative to adversarial adjudication. Critics however lambast this form of ADR as limited in scope with severe shortcoming in the form of power imbalance. The present paper has not denied the issue of power imbalance plaguing the mediation process in certain situation. But, it is submitted that with the help of astute and experienced mediator, such problems could be minimized to substantial degree.

Mediation's potentials are immense. It can be an effective answer to the ills plaguing the modern judicial system. However, in order to be an effective answer, it has to also first address the pressing problems which generally

${ }^{17}$ Jessica Notini, Effective Alternatives Analysis In Mediation, Journal of Conflict Resolution, Vol. XI (2005) pp 35-69 
beset the mediation process. In this regard, the issue of power imbalance surrounding the mediation debate is undeniably legitimate; however, the same can be addressed in a structured manner as shown in this paper.

\section{References}

Abramson, H. I. (2004). Mediation Representation: Advocating in a Problem-solving Process. Ntl Inst for Trial Advocacy.

American Arbitration Association. (2010). Handbook on Mediation. Juris Publishing, Inc.

Boulle, L. (1996). Mediation: Principles, Process, Practice. Butterworths.

Boulle, L., Colatrella, M. T. Jr. (2008). Anthony P. Picchioni, Mediation: Skills and Techniques. LexisNexis Matthew Bender.

Bowling, D. (2003). David Hoffman, Bringing Peace Into the Room: How the Personal Qualities of the Mediator Impact the Process of Conflict. Resolution, Wiley.

Chern, C. (2014). The Commercial Mediator's Handbook. CRC Press.

Golann, D., \& Folberg, J. (2016). Mediation: The Roles of Advocate and Neutral. Wolters Kluwer Law \& Business.

Goodman, A. (2016). Preparing for Mediation. Tarquin.

Hardy, S., \& Rundle, O. (2010). Mediation for Lawyers. CCH Australia Limited.

Lewis, C. (2012). Workplace Mediation Skills: Training Handbook. Globis Mediation Group.

Mackie, K. J. (1991). A Handbook of Dispute Resolution: ADR in Action. Routledge. https://doi.org/10.4324/9780203199718

Noble, C. (1999). Family Mediation: A Guide for Lawyers: Canada law book topics in dispute resolution. Canada Law Book.

Noble, C., Emond, D. P., \& Dizgun, L. L. (1998). Mediation Advocacy: Effective Client Representation in Mediation Proceedings. Emond Montgomery Publications

Picker, B. G. (2003). Mediation Practice Guide: A Handbook for Resolving Business Disputes. American Bar Association.

Salem, R. A., \& Davis, A. M. (1984). Dealing with Power Imbalances in the Mediation of Interpersonal Disputes.

Silver, M. P., \& Barton, P. G. (2001). Mediation and negotiation: representing your clients. Butterworths.

Stitt, A. (2004). Mediation: A Practical Guide. Routledge.

\section{Copyrights}

Copyright for this article is retained by the author(s), with first publication rights granted to the journal.

This is an open-access article distributed under the terms and conditions of the Creative Commons Attribution license (http://creativecommons.org/licenses/by/4.0/). 